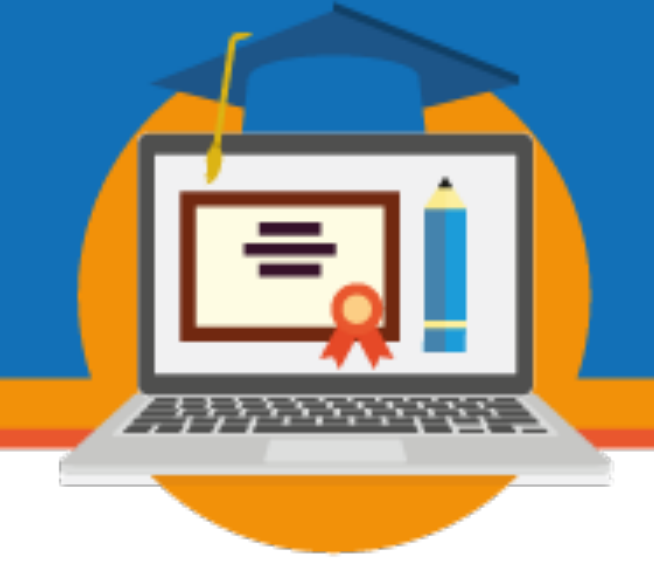

\title{
FÓRUM COMO INTERFACE DE MEDIAÇÃO: UM OLHAR SOBRE A ATUAÇÃO DE PROFESSORES FORMADORES
}

\author{
Elis Ribeiro de Abreu \\ NEAD/UAB/UFMT \\ elisribeirodeabreu@hotmail.com \\ Shirley de Jesus Carvalho \\ NEAD/UAB/UFMT \\ shirley291185@gmail.com \\ Terezinha Fernandes \\ PPGE/Lêtece/NEAD/UFMT \\ terezinha.ufmt@gmail.com
}

Eixo 06: Tecnologias e mediações pedagógicas

\begin{abstract}
Resumo
Este artigo teve como objetivo compreender o uso do fórum como interface de mediação e refletir sobre a atuação do professor formador neste espaço. O estudo foi desenvolvido por meio de pesquisa bibliográfica e análise do registro das mediações feitas por quatro professores formadores, em quatro disciplinas do curso de Licenciatura em Pedagogia, modalidade a distância NEAD/UAB/UFMT, Turmas 1 e 2, polo de Água Boa - MT, em dezoito fóruns de discussão, no ambiente virtual de aprendizagem (AVA). Os resultados apontam a necessidade de ampliação deste campo de atuação dos professores formadores e a fundamental importância da mediação em fóruns de discussão para potencializar a interação entre pares e a construção de aprendizagens significativas.
\end{abstract}

Palavras-chave: Mediação. Professor Formador. Educação a Distância.

\section{Considerações iniciais}

A interação e a mediação docente são imprescindíveis para o desempenho acadêmico no ensino superior, em especial na Educação a Distância (EaD). Estes aspectos, junto a outros, potencializam o processo de ensino e aprendizagem e favorecem o desenvolvimento de uma educação de qualidade. 


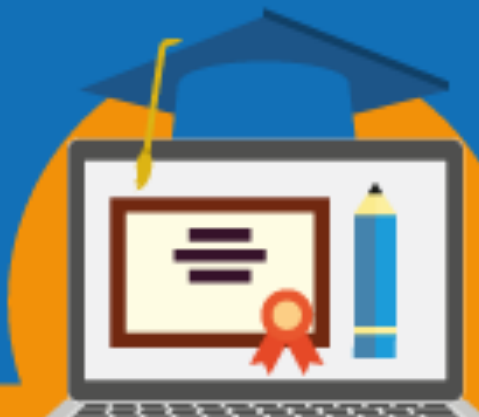

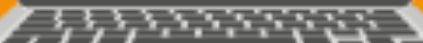

Levando em consideração a importância do papel do professor no processo de aquisição de conhecimentos pelos acadêmicos em cursos superiores na EaD o objetivo de compreender o uso do fórum como interface de mediação e refletir sobre a atuação do professor formador neste espaço, nas Turmas 01 e 02, do curso de Licenciatura em Pedagogia, modalidade a distância, do Núcleo de Educação Aberta e a Distância (NEAD), da Universidade Federal de Mato Grosso (UFMT) ofertado no Âmbito da Universidade Aberta do Brasil (UAB).

Como metodologia o estudo utilizou a pesquisa bibliográfica sobre a mediação e interação na EaD e outros temas e a análise das participações de quatro professores formadores, em dezoito fóruns, de quatro disciplinas no ambiente virtual de aprendizagem (AVA) do curso, utilizando como critérios para a seleção destas disciplinas terem sido ministradas por professores formadores do quadro efetivo da UFMT e terem trabalhado no curso em anos anteriores.

A partir da sistematização dos resultados, este artigo se organiza em quatro seções: a primeira caracteriza-se em um texto teórico que trata da $\mathrm{EaD}$ de modo geral, situando-a no contexto da cibercultura, da educação on-line, dos (AVA) e o diálogo na interface de mediação fórum a partir da interação entre pares. A segunda parte discute os processos metodológicos da pesquisa. A terceira parte traz uma discussão com base nos resultados obtidos da pesquisa, em consonância com as discussões teóricas apresentadas. E a quarta parte apresenta as considerações finais com possiblidades, limites e perspectivas do tema em estudo.

\section{Mediação e interação na EaD}

Ao longo da história da educação no Brasil a formação docente vem ocupando uma das posições centrais nas discussões de pesquisadores e das diretrizes que regulamentam a educação de um modo geral.

Oliveira (2003, p. 34) defende que "a EaD democratiza o acesso ao ensino superior quebrando as barreiras geográficas", sendo este tipo de educação uma forma de suprir a falta 


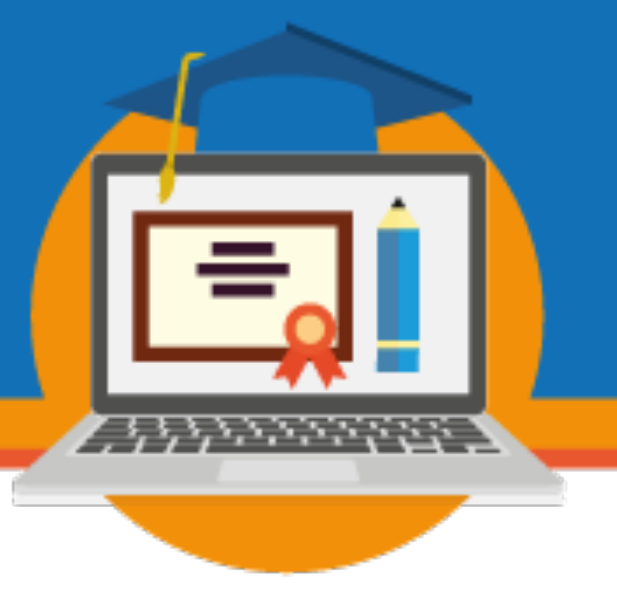

de profissionais capacitados para o mercado de trabalho, aliado a organização social contemporânea e as transformações tecnológicas.

Dentre os diversos documentos que visavam regulamentar a educação a distância, percebe-se grande preocupação das políticas públicas que visam a garantia da qualidade desta modalidade de educação, conforme podemos observar na Lei de Diretrizes e Bases da Educação Nacional (LDB):

Art. 80. O Poder Público incentivará o desenvolvimento e a veiculação de programas de ensino a distância, em todos os níveis e modalidades de ensino, e de educação continuada. $\S 1^{\circ}$. A educação a distância, organizada com abertura e regime especiais, será oferecida por instituições especificamente credenciadas pela União (BRASIL, 1996).

Embora já fosse legalmente prevista em 1996, a EaD só se consolidou efetivamente nos anos seguintes. Lévy (1999) já previa o aumento dos cursos interativos on-line de bases cooperativas, sem distinção entre modalidades "presencial” e "a distância", nas quais o uso das redes de telecomunicação e dos suportes multimídia interativos foram progressivamente integrados nos processos de ensino e aprendizagem reconfigurando a educação.

Com o avanço das redes de internet e hoje dos dispositivos móveis, passamos a vivenciar uma realidade de novas maneiras de comunicação, interação e mediação, as quais propiciam a troca de informações e construção de conhecimento em rede no ciberespaço. Lévy (1999, p.92) define ciberespaço, como:

[...] o espaço de comunicação aberto pela interconexão mundial dos computadores e das memórias dos computadores. Essa definição inclui o conjunto dos sistemas de comunicação eletrônicos (aí incluídos os conjuntos de redes hertzianas e telefônicas clássicas), na medida em que transmitem informações. Consiste de uma realidade multidirecional, artificial ou virtual incorporada a uma rede global, sustentada por computadores que funcionam como meios de geração de acesso.

O autor diz ainda que as relações e as inter-relações humanas que são possíveis no ciberespaço, empregam suas significações, linguagens e "modos de uso". Essas redes nos permitem uma dinâmica de comunicação em tempo real com pessoas distantes, tornando a aprendizagem um processo de cooperação, auxiliando tanto acadêmicos na busca de aprimorar seus conhecimentos, quanto os educadores em sua mediação pedagógica. Desta forma, refletir 


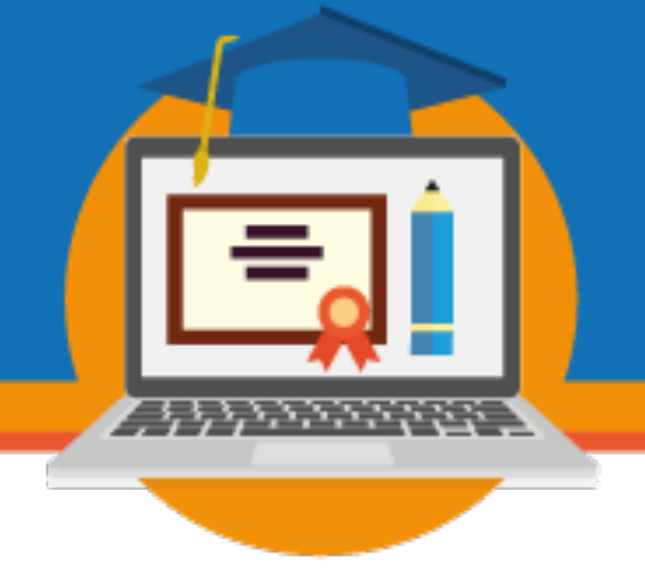

sobre a mediação pedagógica é de suma importância para desenvolver uma EaD que tenha como meta a qualidade da educação e do ensino.

O decreto $n^{\circ} 5622$ de dezembro de 2005 caracteriza a educação a distância "como modalidade educacional na qual a mediação didática pedagógica nos processos de ensino e aprendizagem ocorre com a utilização de meios e tecnologias de informação e comunicação, com estudantes e professores desenvolvendo atividades educativas em lugares ou tempos diversos" (BRASIL, 2005). Assim, podemos dizer que a mediação pedagógica é parte ou alicerce das relações construídas na ação didática para promover encontros entre os sujeitos da aprendizagem de forma colaborativa.

No que diz respeito às tecnologias mais empregadas na educação a distância no contexto da cibercultura, Moran (2011, p. 51) afirma que:

Aos poucos, os ambientes digitais de aprendizagem são utilizados de forma mais abrangente (...). Aumenta também o uso de recursos de comunicação on e off-line, como MSN, skype e webconferência. As novas mídias móveis, como celulares, smartphones e tablets, devem crescer muito a partir de agora, integrando as tecnologias convencionais com as leves e portáteis, facilitando a alunos e professores aprender e ensinar de qualquer lugar e a qualquer hora.

As tecnologias da comunicação vêm provocando mudanças radicais na sociedade por conta do processo de digitalização. Assim, uma nova revolução emerge, a revolução digital. Digitalizada, a informação se reproduz, circula, se modifica e se atualiza em diferentes interfaces. É possível digitalizar sons, imagens, gráficos, textos, enfim uma infinidade de informações. Da máquina de calcular à internet, muita coisa mudou e vem mudando no ciberespaço'.

Isso é conseguido porque as informações contidas nessas linguagens podem ser quebradas em tiras de 1 e 0 que são processadas no computador e transmitidas via telefone, cabo ou fibra ótica para qualquer outro computador, através de redes que hoje circundam e cobrem o globo como uma teia sem centro nem periferia, ligando comunicacionalmente, em tempo quase real, milhões e milhões de pessoas, estejam elas onde estiverem, em um mundo virtual no qual a distância deixou de existir (SANTAELLA, 2001, p. 14).

${ }^{1} \mathrm{O}$ ciberespaço é um "dispositivo de comunicação interativo e comunitário" que se materializa como inteligência coletiva, segundo Lévy, (1999). Assim, "organismos de formação profissional ou à distância desenvolvem sistemas de aprendizagem cooperativa em rede" e (...) "os pesquisadores e estudantes do mundo inteiro trocam idéias, artigos, imagens, experiências ou observações em conferências eletrônicas organizadas de acordo com interesses específicos" (LÉVY, 1999, p.29).

\section{SEMINÁRIO DE EDUCAÇÃO A DISTÂNCIA}




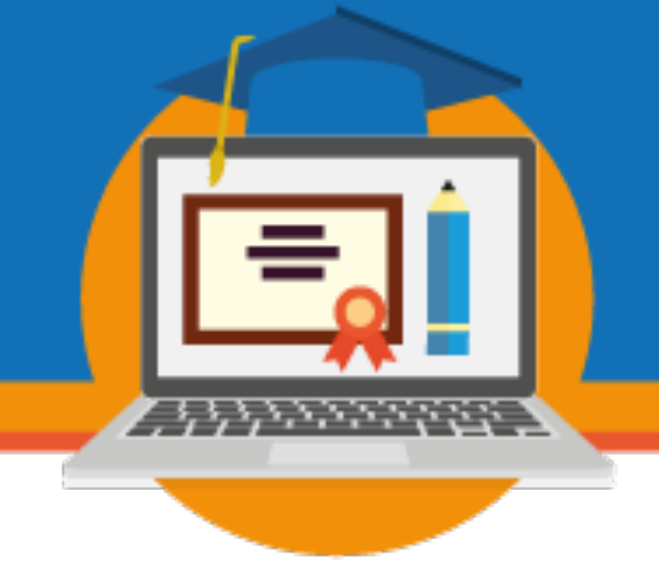

A autora aponta que, para conviver nessa sociedade, é preciso compreender diferentes linguagens e mídias, suas naturezas comunicacionais específicas e suas implicações políticosociais que mediaram cada geração tecnológica de formas diferenciadas.

Para além dos espaços e tempos de aprendizagem, as potencialidades comunicacionais e interativas da cibercultura contribuem para a ressignificação de práticas pedagógicas, com o desenvolvimento das tecnologias digitais, num contexto de cultura digital marcada por chips, e-mails, cartões eletrônicos, redes de computadores, smartphone, tablet, comunidade on-line e diversas mídias sociais apresentam a cultura contemporânea, ou seja, marcada pela tecnologia digital.

Dada a amplitude e o ritmo das transformações tecnológicas ocorridas, as mudanças sociais e culturais implicam em transformações no universo digital, com os dispositivos móveis, conferências on-line e interfaces de colaboração como grupos de Whatsapp e outros, por meio dos quais as pessoas estão cada vez mais interligadas, conectando-se e interagindo, independentemente de sua posição geográfica.

Sabemos que, diante de tais mudanças, é fundamental considerar que alguns ajustes devem ser pensados nos sistemas de educação e formação. Atualmente a EaD tende a incluir as redes de comunicação interativas, hipermídia e demais tecnologias intelectuais da cibercultura, mas o essencial não se encontra nos meios utilizados; encontra-se em compreender os novo estilos de pedagogia, em que são favorecidas, ao mesmo tempo, as aprendizagens personalizadas e a aprendizagem coletiva. O conhecimento encontra-se, nesse contexto, acessível on-line em hipertextos, em aulas interativas e em simulações em tempo real.

É importante destacar que a educação vem passando por um período de transformações e construções, isso devido a inserção das tecnologias digitais, e nesse contexto, devemos considerar a figura imprescindível do professor na mediação a ser feita na EaD. De acordo com Masetto (2000, p.144-5):

Mediação pedagógica é uma atitude, o comportamento do professor que se coloca como facilitador, incentivador ou motivador da aprendizagem, que se apresenta com a disposição de ser uma ponte entre o aprendiz e sua aprendizagem - não uma ponte estática, mas uma ponte "rolante", que ativamente colabora para que o aprendiz chegue aos seus objetivos.

\section{SEMINÁRIO DE EDUCAÇÃO A DISTÂNCIA}

Diálogos sobre EaD e uso das TDIC na educação: regulamentação em tempos recentes 


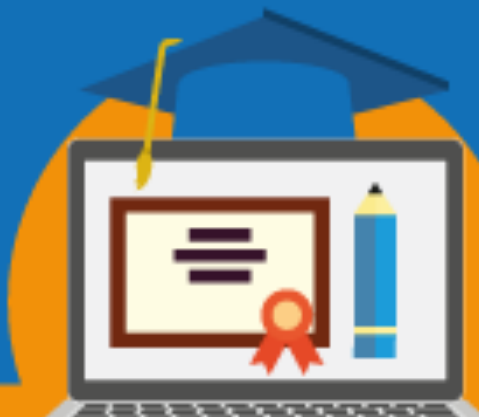

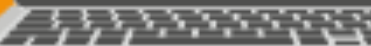

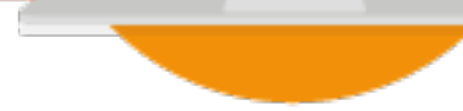

Embora estejamos vivendo em uma sociedade cada vez mais mediada por tecnologias digitais em que as distâncias são menos relevantes devido ao virtual, é importante que se tenha uma visão crítica para que a perspectiva de uso dos AVA não nos leve a esquecer os cuidados com a mediação do professor formador nos processos de ensino e aprendizagem.

É imprescindível questionar qual é o propósito pedagógico de professores formadores utilizarem determinadas interfaces de comunicação em detrimento de outras e, também, os modos desenvolver a ação educativa no contexto da cibercultura com o uso, por exemplo, de um fórum como interface de interação que requer a mediação constante.

Para Lopes e Xavier (2007) é importante também que o professor tenha uma postura ativa e dialógica nos AVA, fazendo-se presente e sempre disposto a apoiar os acadêmicos durante o processo. Portanto, a interface por si só não proporciona interação, para tal, é necessário que os professores compreendam que as potencialidades de aprendizagem são mediadas. Eles devem estimular os acadêmicos a troca de conhecimentos e incentivá-los a percorrer, por conta própria, os caminhos do aprendizado.

Mello (2004, p.93) afirma que "zelar pela aprendizagem dos alunos exige do professor transformar sua relação com o saber, seu modo de ensinar e sua identidade". O significado da informação, da aprendizagem e da troca de conhecimento entre os indivíduos e como estes são compreendidos pelos envolvidos é um processo de extrema importância para o entendimento da sociedade nos dias atuais, na qual o poder da informação, do conhecimento e das tecnologias digitais têm um peso fundamental.

Quando os professores utilizam adequadamente os artefatos tecnológicos e criam ambientes de aprendizagem mediados, estes possibilitam também aos acadêmicos a construção do conhecimento individual e coletivo, contribuindo para a sua formação social e humana.

\section{Metodologia}

A metodologia utilizada neste estudo foi a pesquisa bibliográfica que possibilitou a construção de um referencial teórico sobre a mediação e interação na EaD situando-a no 


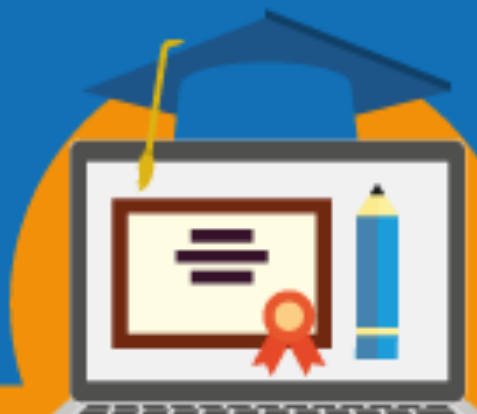

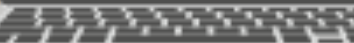

F

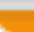

contexto da cibercultura. A observação e análise das participações de professores formadores², em disciplinas no Ambiente Virtual de Aprendizagem (AVA), do curso de Licenciatura em Pedagogia, modalidade a distância, do NEAD/UAB/UFMT, teve como o objetivo de compreender o uso do fórum como interface de mediação e refletir sobre a atuação do professor formador neste espaço.

A amostra contou com a análise das participações de quatro professores formadores das disciplinas de Antropologia II, Pedagogia da Infância II, Sociologia I e Múltiplas Linguagens: Linguagem e Pensamento I, utilizando como critérios para a seleção destas disciplinas terem sido ministradas por professores formadores do quadro efetivo da UFMT e terem trabalhado no curso em anos anteriores. Destas quatro disciplinas foi eleita a interface Fórum Permanente ou Reflexivo como objeto de análise, e esta escolha se deu por este ser o espaço mais usado para a discussão e reflexão sobre os temas/conteúdos nas disciplinas do curso em pauta.

\section{Resultados e discussões}

O curso de Licenciatura em Pedagogia, modalidade a distância, do NEAD/UAB/UFMT, objetiva a formação de profissionais para a etapa educativa destinada às crianças de 0 a 10 anos e teve início no ano de 2017, com 240 vagas, sendo estas divididas em quatro Polos do Estado de Mato Grosso: Água Boa, Canarana, Juara e Primavera do Leste, cada munícipio com três turmas de 20 acadêmicos e desenvolvido por meio de um ambiente virtual de aprendizagem (AVA) e suas interfaces de comunicação. Segundo Almeida (2003, p. 331) os AVAs são:

Sistemas computacionais disponíveis na internet, destinados ao suporte de atividades mediadas pelas tecnologias de informação e comunicação. Permitem integrar múltiplas mídias, linguagens e recursos,

\footnotetext{
2 No PPC do curso de Licenciatura em Pedagogia, modalidade a distância NEAD/UAB/UFMT, professor formador é o professor especialista que assessora os orientadores acadêmicos/tutores quanto ao estudo e à discussão dos conteúdos do material didático do curso, durante os encontros mensais que se realizam na universidade ou nos Polos Presenciais para formação continuada dos orientadores. $O$ professor especialista/formador fica à disposição dos orientadores, podendo a comunicação ser feita pelo telefone, web conferência e pelo ambiente virtual de aprendizagem do curso e outros meios. Este professor é responsável pela condução de determinada disciplina ou módulo no curso.
}

\section{SEMINÁRIO DE EDUCAÇÃO A DISTÂNCIA}


Belloni (2001) afirma que um dos papéis do professor na EaD é o de constituir-se em um parceiro dos estudantes no processo de aprendizagem.

Com esta intenção no quadro a seguir apresentamos os resultados da observação da atuação dos professores formadores nos fóruns das disciplinas eleitas para análise.

Quadro 1: Fóruns de discussão

\begin{tabular}{|l|l|}
\hline \multicolumn{1}{|c|}{ Disciplina } & \multicolumn{1}{|c|}{ Mediação do Professor Formador } \\
\hline Antropologia II & Não localizamos indícios de participação/mediação. \\
\hline Pedagogia da Infância II & $\begin{array}{l}\text { Localizamos uma participação para direcionamento das } \\
\text { discussões à obtenção do resultado desejado. }\end{array}$ \\
\hline Sociologia I & Não localizamos indícios de participação/mediação. \\
\hline $\begin{array}{l}\text { Múltiplas Linguagens: } \\
\text { Linguagem e Pensamento } \\
\text { I, II e III }\end{array}$ & Não localizamos indícios de participação/mediação. \\
\hline
\end{tabular}

Fonte: Elaborado com os dados das observações pelas pesquisadoras.

Foi possível observar, em linhas gerais, a quase inexistência de mediação dos professores formadores, com exceção de uma das disciplinas, todavia, foi apenas no sentido de intervir na condução da discussão, sem estímulo ou motivação à participação e aprendizagem. Apesar disso houve a participação por parte dos acadêmicos respondendo as questões propostas para discussão, mas sem a interação com o professor formador.

Por meio dos registros publicados pelos acadêmicos nos fóruns foi possível identificar dificuldades apontadas por eles durante o desenvolvimento de cada disciplina. Durante os estudos nos deparamos com ocorrências em que os acadêmicos direcionavam perguntas para os próprios colegas nas discussões, uma vez que o professor formador não participava da interação e nem mediava o debate.

Para Vilarinho e Sande (2003, p.11) o professor no AVA deverá “esclarecer dúvidas, interagir com os alunos, ser comunicativo e claro nas suas comunicações, estar engajado nas atividades do curso e valorizar o espírito crítico e criativo do aprendiz". O que reforça a existência de grande preocupação com a mediação do professor formador nos fóruns em disciplinas na $\mathrm{EaD}$. 


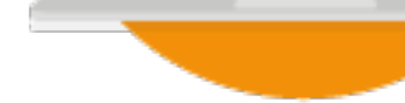

Nesse contexto, a pesquisa obteve como resultados que o fórum como interface de mediação pressupõe a participação constante de professores formadores durante o processo de ensino e aprendizagem dos acadêmicos. De acordo com Kearsley (2011), a falta de retorno por parte do educador revela-se como uma das maiores reclamações dos estudantes em relação aos cursos on-line.

Nesse sentido é de fundamental importância a atuação do professor formador no sentido de intervir de maneira ativa nos fóruns de cada disciplina ministrada favorecendo ao acadêmico alcançar melhores resultados, por meio do estímulo à interação com os outros e à reflexão como forma de aprimoramento na construção da aprendizagem significativa.

\section{Considerações Finais}

A educação a distância na área de formação de professores tem gradativamente ampliado o acesso a um número maior de pessoas, que não poderiam cursar uma graduação por meio de outra modalidade por serem, em sua maioria, adultos e trabalhadores. Nesse sentido, é preciso perceber a importância do professor formador como mediador da aprendizagem nesses processos de formação.

Sendo assim, atingimos o objetivo de compreender o uso do fórum como interface de mediação e refletir sobre a atuação do professor formador neste espaço, no curso de Licenciatura em Pedagogia, modalidade a distância, do Núcleo de Educação Aberta e a Distância (NEAD), da Universidade Federal de Mato Grosso (UFMT), nas disciplinas analisadas.

De certa forma evidenciamos que o fórum não tem consistido em uma interface de mediação e sim de postagem de atividades pelos acadêmicos que, em algumas situações, dialogam entre si. E a falta da participação dos professores formadores implica na ausência de mediação às possíveis dificuldades de aprendizagem dos acadêmicos. Estes aspectos apontam

\section{SEMINÁRIO DE EDUCAÇÃO A DISTÂNCIA}




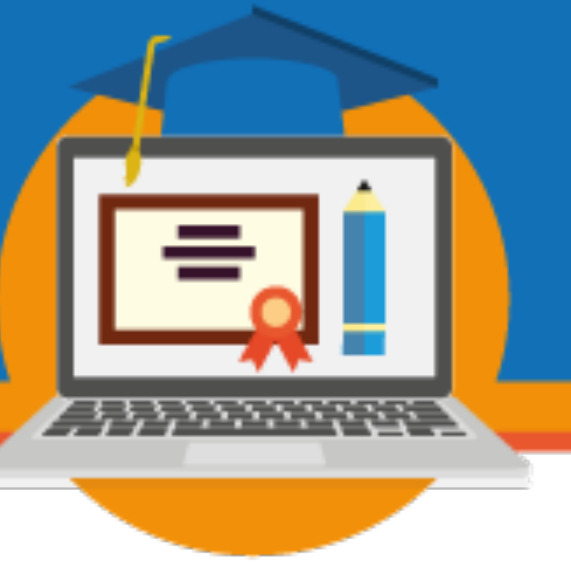

que ainda há muito a se fazer para uma melhoria considerável na qualidade dos processos de mediação existentes no curso analisado.

Acreditamos que a discussão feita neste estudo com as análises dos fóruns, apesar de se tratar de um estudo pontual, sugere um aprofundamento neste campo de pesquisa, para identificar mecanismos que possam auxiliar, tanto equipes pedagógicas de cursos, quanto professores formadores, na melhoria do planejamento dos processos que envolvem a definição de papéis e de atuação nos processos de mediação, característicos da EaD e favorecedores de uma postura mais ativa e colaborativa dos acadêmicos na sua própria aprendizagem.

\section{Referências}

ALMEIDA, Maria Elizabeth Bianconcini de. Educação a Distância na Internet: abordagens e contribuições dos ambientes digitais de aprendizagem. Educação e Pesquisa, Pontifícia Universidade Católica de São Paulo, São Paulo, v.29, n.2, p. 327-340, jul./dez. 2003. http://www.scielo.br/pdf/ep/v29n2/a10v29n2.pdf Acesso em 10/08/2018

BELLONI, Maria Luiza. O que é Mídia e Educação. Campinas: Autores Associados, 2001.

BELLONI, Maria Luiza. Educação a distância. 3. ed. Campinas: Autores Associados, 2003.

BRASIL. Lei de Diretrizes e Bases da Educação Nacional. Lei número 9394, 20 de dezembro de 1996. Senado Federal. Senador Ramez Brasília 2005. Disponível https://www2.senado.leg.br/bdsf/bitstream/handle/id/70320/65.pdf Acesso em 24/072018

BRASIL, Câmara dos Deputados. Legislação Informatizada. Decreto $\mathbf{n}^{\mathbf{0}} \mathbf{5 . 6 2 2}$, DE 19 DE DEZEMBRO DE 2005. https://www2.camara.leg.br/legin/fed/decret/2005/decreto-5622-19dezembro-2005-539654-publicacaooriginal-39018-pe.html

KEARSLEY, G. Educação on-line: aprendendo e ensinando. Tradução Mauro de Campos Silva. São Paulo: Cengage Learning, 2011.

LÉVY, Pierre. Cibercultura. Tradução de Carlos Irineu da Costa. São Paulo, Ed. 34, 1999.

LOPES, Maria Cristina L. Paniago; XAVIER, Selma Lúcia da Costa. A afetividade nas interrelações professores e alunos no ambiente digital. Revista Brasileira de Aprendizagem 


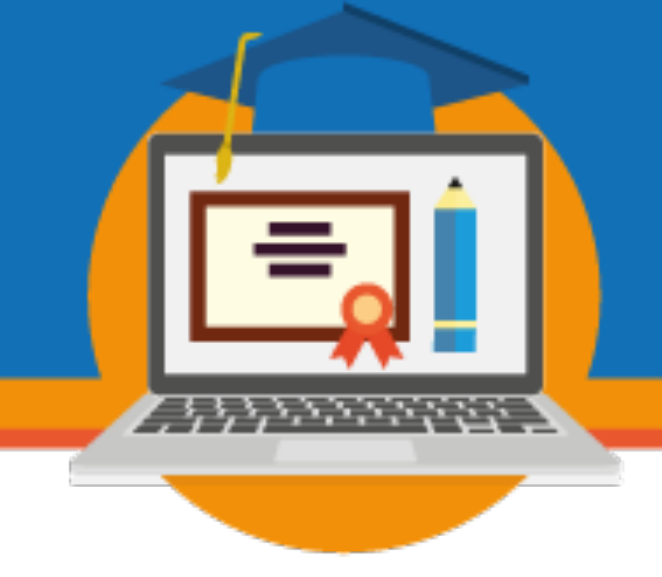

Aberta e a Distância. Associação Brasileira de Educação à Distância. São Paulo. v.6, p. Dez 1-17.2007.Disponível em http://seer.abed.net.br/pndex.php/RBAAD/artpcle/vpew/184/63

MASETTO, M. T.; MORAN, J. M.; BEHRENS, M. A. Novas tecnologias e mediação pedagógica. Campinas: Papirus, 2000.

MORAN, José Manuel. Desafios da educação a distância no Brasil. In: ARANTES, Valéria Amorim (org.). Educação a distância: pontos e contrapontos. São Paulo: Summus, 2011.

MELLO, G.N. Educação Escolar Brasileira: o que trouxemos do século XX. Rio de Janeiro: Artmed, 2004.

OLIVEIRA, Gerson Pastre de. O fórum em um ambiente virtual de aprendizado colaborativo. Disponível em: https://www.researchgate.net/publication/267714580_O_FORUM_EM_UM_AMBIENTE_V IRTUAL_DE_APRENDIZADO_COLABORATIVO

OLIVEIRA, Elsa Guimarães. Educação a distância na transição paradigmática. Campinas, SP: Papirus, 2003 - Coleção Magistério: Formação e Trabalho Pedagógico.

PRETI, Oreste. Educação a distância: fundamentos e políticas. Cuiabá: EdUFMT, 2009.

SANTAELLA, L. A Matrizes da linguagem e pensamento: sonora, visual, verbal. São Paulo: Iluminuras, 2001.

VILARINHO. Lúcia Regina Goulart; SANDE, Iêda Carvalho. Formação Continuada de Professores em Cursos on-line. Novas Perspectivas no Processo Ensino-Aprendizagem? In: Anais do Simpósio Brasileiro de Informática na Educação. 14., 2003, Rio de Janeiro. Porto Alegre: Sociedade Brasileira de Computação, 2003, p: 05-14. 